\title{
Hiob - Vom Gottesfürchtigen zum Repräsentanten Israels
}

\author{
Studien zur Buchwerdung des Hiobbuches und zu seinen Quellen
}

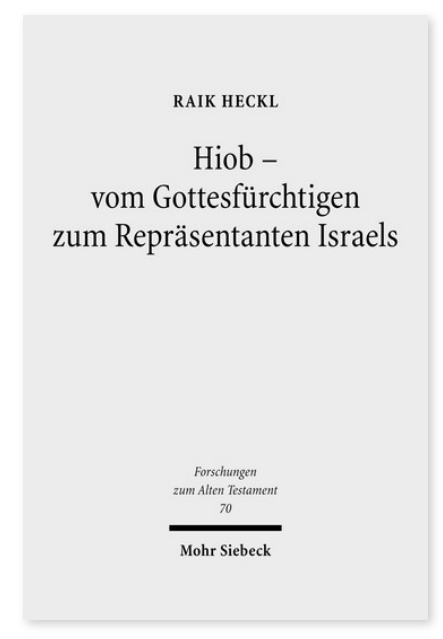

2010. X, 528 Seiten. FAT 70

ISBN 978-3-16-151111-0

DOI 10.1628/978-3-16-151111-0

eBook PDF $144,00 €$

ISBN 978-3-16-150337-5

Leinen $144,00 €$
Raik Heckl weist nach, dass das Gegenüber von Prosa und Dichtung im Hiobbuch dadurch zustande kam, dass eine ältere Hiobdichtung mit eigener Kohärenzstruktur und Intention nachträglich erzählerisch gerahmt wurde.

In der älteren Dichtung wurde Hiob als frommer Heide dargestellt, der an seiner Gottesbeziehung im Leiden festhält und dem sich in den Gottesreden Jhwh, der Gott Israels, in einer persönlichen Gottesbegegnung offenbart. Während sich die Dichtung in exemplarischer Weise mit der Frage nach Gottes Stellung zum Leiden beschäftigt, werden Thema und Hauptfigur in der Rahmenerzählung geschichtstheologisch umgedeutet. Hiob, der hier von vornherein als Jhwh -Verehrer erscheint, wird durch eine strukturbildende Verarbeitung von 1 Sam 1-4 zum Repräsentanten des Geschicks des Volkes Israel gemacht. Die Wiederherstellung des unschuldig Leidenden weist auf eine zukünftige Wiederherstellung Israels hin, wodurch das deuteronomistische Geschichtskonzept der Samuelis- /Königebücher kontrastiert wird.

Raik Heckl ist seit 2011 Heisenbergstipendiat der Deutschen Forschungsgemeinschaft an der Universität Tübingen und seit 2013 apl. Professor am Institut für Alttestamentliche Wissenschaft an der Universität Leipzig.

Jetzt bestellen:

https://mohrsiebeck.com/buch/hiob-vom-gottesfuerchtigen-zum-repraesentanten-israels-9783161511110?no_cache=1 order@mohrsiebeck.com

Telefon: $+49(0) 7071-923-17$

Telefax: $+49(0) 7071-51104$ 